\title{
Technology-Facilitated Violence Against Women in Singapore: Key Considerations
}

\author{
Laura Vitis
}

\begin{abstract}
Technology-facilitated violence against women (TFVW) is readily becoming a key site of analysis for feminist criminologists. The scholarship in this area has identified online sexual harassment, contact-based harassment, imagebased abuse, and gender-based cyberhate - among others - as key manifestations of TFVW. It has also unpacked the legal strategies available to women seeking formal justice outcomes. However, much of the existing empirical scholarship has been produced within countries like the United States, United Kingdom, and Australia, and there has been limited research on this phenomenon within South East Asia. As such, this chapter maps how technology is shaping Singaporean women's experiences of gendered, sexual, and domestic violence. To do so, it draws upon findings from a research project which examined TFVW in Singapore by utilizing semistructured interviews with frontline workers in the fields of domestic and sexual violence and LGBT services. Drawing from Dragiewicz et al.'s (2018) work on technologyfacilitated coercive control (TFCC), I argue that victims-survivors of dating, domestic, and family violence need to be provided with support that is TFCC informed and technically guided. I also suggest that further research is needed to fully understand the prevalence and nature of TFVW in the Singaporean context.
\end{abstract}

Keywords: Surveillance; Technology-facilitated violence against women; technology-facilitated coercive control; coercive control; Singapore; domestic violence

The Emerald International Handbook of Technology-Facilitated Violence and Abuse, 407-425 Copyright (C) 2021 Laura Vitis

Published by Emerald Publishing Limited. This chapter is published under the Creative

Commons Attribution (CC BY 4.0) licence. Anyone may reproduce, distribute, translate and create derivative works of these chapters (for both commercial and non-commercial purposes), subject to full attribution to the original publication and authors. The full terms of this licence may be seen at http://creativecommons.org/licences/by/4.0/legalcode.

doi:10.1108/978-1-83982-848-520211031 


\section{Introduction}

Technology-facilitated violence against women (TFVW) has become a key site of analysis for feminist criminologists. The scholarship in this area has identified online sexual harassment, contact-based harassment, image-based abuse (IBA), and gender-based cyberhate - among others - as key manifestations of TFVW (Dragiewicz et al., 2019; Jane, 2017; Powell, Henry, Flynn, \& Scott, 2019). It has also explored the legal strategies available to women seeking formal justice outcomes. However, much of the existing empirical scholarship has been produced within countries like the United States, United Kingdom, and Australia, and there has been comparatively less research on this phenomenon in South East Asia. This is a key gap considering the important role that the legislative, service sector, and sociopolitical landscape plays in both support provision and help-seeking. This chapter examines how technology has shaped Singaporean women's experiences of dating, domestic, and family violence. It begins by outlining what is known about TFVW in the Singaporean context and the criminal and civil mechanisms available for redress. The chapter then draws upon findings from a research project which examined TFVW in Singapore, utilizing semistructured interviews with frontline workers in the fields of domestic and sexual violence and LGBT support. Drawing from Dragiewicz et al.'s (2018) work on technology-facilitated coercive control (TFCC), I explore the modalities of TFCC reported in these accounts and argue that tech-abuse training should be provided to frontline workers to ensure that more well-known forms of TFVW, such as "camera sexual voyeurism (CSV)," do not obscure the other forms located within the domestic or intimate partner context. I also argue that victims-survivors of dating, domestic, and family violence need to be provided with support that is TFCC informed and technically guided.

\section{Technology and Violence Against Women}

As noted throughout this collection, feminist scholars, researchers, and advocates have highlighted how contemporary technologies are woven into women's experiences of violence. Importantly, researchers have brought to the fore the diverse modalities of abuse and their distribution across women's lifeworlds. Research into IBA, for instance, has shown how strangers, intimate partners, ex-partners, acquaintances, and networks have nonconsensually produced, possessed, altered, distributed, and threatened to distribute women's intimate images for the purposes of harm, humiliation, profit, and control (Henry, Powell, \& Flynn, 2017; Powell et al., 2019; Vitis, 2020a). This literature has also highlighted how women are subject to unsolicited pictures of men's genitals across various mediated contexts (Hayes \& Dragiewicz, 2018). More broadly, gender-based invective, harassment, dismissal, and criticism have become embedded in women's participation in online spaces (Jane, 2017). For example, recent research with Australian female Tinder users showed that they routinely experienced the following: sexualized messages; hostility; appearance judgment; possessive/controlling messages; and unsolicited nude images on the platform (Gillet, 2019). Gillet's (2019) work noted that sexual double standards and gendered invective are used to both justify and sustain this harassment. This finding is affirmed by Thompson's (2018, p. 83) analysis of Tinder 
Nightmares and ByeFelipe, ${ }^{2}$ which found that when sexualization was challenged, men deployed sexual double standards to justify their behavior. This included assertions that dating apps are ".. transactional space[s] for sex where women are to be used as a "free' source of sex" and women who use dating apps invite sexualization (Thompson, 2018, p. 83).

One of the many contributions of this body of work is that it demonstrates how technologies have further despatialized violence against women (VAW) by separating it from physical space (Harris \& Woodlock, 2019). Concomitantly, it has shown that online harassment and abuse targeted at women and those "othered" within social spaces serves to

(re)draw boundaries in, around, and between virtual spaces... which shape the rules and norms concerning which individuals and groups are endowed with status and legitimated to participate in these spaces, and those who are not. (Harmer \& Lumsden, 2019, p. 13)

Jane's (2017) examination of Australian journalists' experiences of genderbased cyberhate and subsequent self-censorship demonstrates how harassment "mutes" women's public presence (p. 54). This was also affirmed in Gillet's (2019) research which found that participants decided to withdraw from Tinder and/or delete their accounts "... to mitigate intimate intrusions in a context where they were likely to occur" (p. 92). Therefore, these different forms of abuse also reterritorialize social spaces and entrench sociopolitical hierarchies (Harmer \& Lumsden, 2019).

These observations are prominent in the contemporary domestic violence literature, which highlights how digital and internet technologies are embedded within practices of coercive control in ways that compromise women's ability to seek freedom from violence and render abusers "omnipresent" (Dragiewicz et al., 2019; Southworth, Finn, Dawson, Fraser, \& Tucker, 2007). Indeed, Dragiewicz et al. (2018) have developed the term "technology-facilitated coercive control" (TFCC) to describe the "technological and relational aspects of patterns of abuse against intimate partners" (p. 69). Their research has shown that abusers use communication and internet technologies ${ }^{3}$ to infiltrate women's spaces of autonomy, control at a distance, and reduce women's opportunities to separate and sever contact (Dragiewicz et al., 2018). Abusers use these technologies to enact control during separation by unsettling women's ability to create "safe distances" and spaces (Bruton \& Tyson, 2017; Hand, Chung, \& Peters, 2009; Maher, McCulloch, \& Fitz-Gibbon, 2017; State of Victoria, 2016, p. 17). Moreover, this literature suggests that certain elements of TFCC, like stalking, tracking, and restricting phone usage, are key risk factors for intimate partner homicide (Domestic and Family Violence Death Review, 2017).

As is evident from this brief overview, it is important to remain alert to the wider landscape of TFVW to fully encapsulate the ubiquity of these practices across women's lifeworlds and their imbrication with sociopolitical subjectivities. As such, this chapter aims to continue the project of this wider body of literature by exploring the role of technology in women's experiences of dating, domestic, 
and family violence in Singapore. In the following sections, I map the current literature on Singaporean women's experiences of TFVW, including the legislative landscape within which they are situated. I also address some of the gaps on the relationship between domestic violence, coercive control, and technology in this burgeoning field.

\section{Technology-Facilitated Violence Against Women in the Singaporean Context}

Research into women's experiences of domestic violence in the Singaporean context has included limited large-scale prevalence studies and small studies that rely on service data and police statistics (Chan, 2013, p. 329). For example, Bouhours, Chan, Bong, and Anderson (2013) conducted the International Violence Against Women Survey in Singapore. In the survey, 6.1\% of Singaporean women reported they had experienced physical or sexual violence from an intimate partner in their lifetime. Around $2 \%$ of women reported either physical or sexual violence in a current relationship. Additionally, $22.4 \%$ of women reported controlling behaviors by an intimate partner (e.g., angry if she speaks to other men, insists on knowing where and with whom she is, limits contacts with her family and friends, tracks her whereabouts, suspicious of her being unfaithful), and $7.1 \%$ reported emotionally abusive behaviors by an intimate partner (e.g., damages/destroys her property, harms/threatens to harm her children, threatened to kill himself, threatens to kill her, harms/threats to harm others close to her, threatens to hurt her or her children if she leaves him).

Within these wider studies there has been no exploration to date of the ways in which technology shapes VAW. Despite this, recent research, court/news reports, and reports from a local women's organization demonstrate that IBA, such as CSV and threats to distribute intimate images, has become a prominent issue in Singapore (AWARE, 2019a; Vitis, 2020a). Since 2004, men across Singapore have been prosecuted for using phones and spy cameras to record underneath women's clothes in public spaces like Mass Rapid Transit (MRT) stations and shopping centers (Vitis, 2020). This practice, referred to as "upskirting," 4 has also been recognized by Singaporean police, who have reported a rise in "insult of modesty" cases, ${ }^{5}$ from 571 in 2013 to 629 in 2016 (Chong, 2015). The prominence of IBA has been affirmed in Vitis, Joseph, and Mahadevan's (2017) review of case file data from the Sexual Assault Care Centre (SACC), which found that in $2016,18 \%$ of client reports involved the use of technology to either facilitate or record violence. Of these 60 cases, 29 involved IBA incidents including the nonconsensual distribution of intimate images; threats to distribute intimate images; and CSV (Vitis, 2020a). Additionally, in 2019, the SACC found that of the 124 client reports involving technology, more than 50\% involved IBA (AWARE, 2019a).

Public recognition of IBA came to the fore in 2019 with media coverage of several key IBA cases. In April 2019, the media reported that Monica Baey - a student at the National University of Singapore (NUS) - was filmed in the 
University's residential showers by a fellow student. This case circulated widely in the media after Baey took to Instagram to expose the perpetrator and call into question the police's decision to give him a warning and the University's decision to suspend him for a semester (Ang, 2019a). After these posts, her case gained a large online following and local news coverage. Moreover, students at NUS objected to the University's response to the case and NUS subsequently altered its policies on investigating sexual harassment on campus (Ang, 2019a).

The wider scale of the problem was further affirmed in a recent AsiaOne investigation which found that men were using private Telegram group chats entitled "SharingIsCaring" and "SG Nasi Lemak" to circulate nonconsensual and voyeuristic images of women and girls riding public transport, including voyeuristic images of children in school uniforms (Ang, 2019b). The proliferation of nonconsensual image sharing between men was also shored up by recent reports that CSV or "upskirting" images were being disseminated on popular Singaporean countercultural message board forums like Sam's forum (Alkhatib, 2019). This wider practice is evident in the disclaimers on Sam's forum private image exchange threads, which explicitly dissuade users from sharing "snipe" images (a term for CSV or "upskirt" images) while inviting them to "trade pix of [their] sexcapades with, wives, girlfriends \& broads" (Sam's Forum, 2020). Although these varying sources of information on IBA cannot provide an overall sense of prevalence, taken together, they do indicate the ways in which IBA is shaping women's experiences of sexual violence and public space in Singapore.

As has been established throughout this collection, TFVW comprises varying modalities and IBA constitutes just one (important) modality within this continuum. For example, in the SACC's review of its 2016 case files, contact-based harassment was one of the main forms of TFVW reported by clients (Vitis, Joseph, \& Mahadevan, 2017). Contact-based harassment involved the use of communication technologies to facilitate unwanted sexual contact and included behaviors such as sending explicit, coercive, and sexually harassing messages and posting negative comments on social media. In these cases, perpetrators were employers, colleagues, strangers, teachers, and unknown persons (Vitis et al., 2017).

The public discourse on TFVW has featured IBA prominently because of high volume media coverage of CSV cases perpetrated by strangers in public spaces (Vitis, 2020b). While it is greatly important that these forms of IBA are addressed, it is also important to recognize how technology shapes other, more hidden, forms of abuse. As my own (Vitis, 2020a, p. 27) research into IBA in Singapore found, several cases took place in the private sphere. This research found that in cases where perpetrators threatened to distribute intimate images, they would threaten to share these images with family members. Additionally, threats or coercion often occurred in more hidden contexts like the workplace or in contexts where perpetrators used citizenship status to leverage their harassment. Therefore, as the wider literature on TFVW shows, it is crucial to foreground the continuum of violence, in order to highlight how technology comes to shape women's everyday experiences of violence/harassment. 
There are several reasons why it is important to examine the wider patterns of TFVW in the Singaporean context. First, this research can address gaps in the literature and counter the hierarchies of feminist knowledge that privilege the experiences of western or northern women (Carrington, Bull, \& Vitis, 2020; Mohanty, 2012). Secondly, despite media reports, public outrage, and evidence from local women's groups (AWARE, 2019a; Vitis, 2020a; Vitis et al., 2017), "gendering" TFVW is complex. This is particularly evident in the media/online discourse on IBA. For instance, my examination of the Straits Times' coverage of "upskirting" cases found that while "upskirting" was roundly condemned, the media discourse did not contextualize CSV in relation to VAW (Vitis, 2020). Similarly, research examining public responses to the Monica Baey case on popular online message boards has shown that while there was widespread condemnation of the perpetrator, there was less overt recognition of this case as part of the wider continuum of sexual VAW (Vitis, Naegler, \& Ahmad Salehin, 2019).

The gendered dimensions of women's experiences of TFVW can be occluded by such conflations and absences. For example, in my study (Vitis, 2020a), I found that threats to distribute intimate images were used as a tool of sexual assault and coercion. Vitis et al.'s (2017) research into TFVW in the SACC also found that contact-based harassment was imbricated within sexual harassment in the workplace. Moreover, at AWARE's recent panel session on technologyfacilitated sexual violence, clients reported that perpetrators had threatened to distribute intimate images taken during consensual sexual encounters and engaged in CSV while stalking them (Tan, 2019). This demonstrates how women's various experiences of TFVW intersect with wider patterns of sexual violence, workplace harassment, dating violence, and coercive control (Dragiewicz et al., 2019).

Relatedly, Association of Women for Action and Research (AWARE) has reported that victims of threats to distribute intimate images and CSV have refrained from going to police because they have been told by others that they are to blame for what happened (Tan, 2019, p. 15). Therefore, the gendered myths that have long surrounded sexual violence continue to constrain women's decisions to come forward, tell friends, family, and police, and seek freedom from violence. These examples demonstrate the importance of research which emphasizes the location of TFVW along the continuum of sexual violence and its imbrication within women's lifeworlds.

\section{Legislative Landscape}

Until very recently, IBA (both the nonconsensual production and distribution of intimate images) has been dealt with under a range of laws in Singapore. Prior to January 2020, sexual voyeurism cases were prosecuted under the "insult of modesty" offense. This is a nonphysical sexual harassment offense which defines prohibited behaviors as instances where a person says:

any word, makes any sound or gesture, or exhibits any object, intending that such word or sound shall be heard, or that such 
gesture or object shall be seen by such woman, or intrudes upon the privacy of such woman. (Penal Code 2008 Rev. Ed., section 509)

Additionally, those who have been found possessing or sharing images have been charged with making, distributing, or possessing an obscene film (Films Act 1998 Rev. Ed., section 29.1, 29.3, 30.1). ${ }^{6}$ Also, in 2014, the Protection from Harassment Act (POHA) 2014, extended the substantive definition of harassing behavior to include electronic means and provided more comprehensive protection orders for victims outside intimate relationships (Goh \& Yip, 2014). As such, victims are potentially able to obtain a protection order from the courts, after their images have been shared without consent.

There are clear limits with this legislation. While sexual voyeurism cases have been prosecuted under the insult of modesty offense (c.f. Chong, 2017), it is overly broad and does not address the varying modalities of IBA, such as the distribution of intimate images without consent, or threats to distribute intimate images without consent. It is also a nonarrestable offense and as such police are unable to arrest without a warrant, and the victim must first make a Magistrate's complaint prior to police intervention, which can act as a deterrent to reporting. Additionally, the offenses under the Films Act 1998 are used to target the production and distribution of "pornography." While this has been used in successful prosecutions, it punishes perpetrators for "obscenity," not for violating women's consent, bodily autonomy, or privacy. This also has the potential to conflate the nonconsensual production and use of these images with consensual pornography.

Parliament has recently reformed the penal code to better address acts of technology-facilitated violence. In February 2019, the Criminal Law Reform Bill 2019 was introduced into Parliament. This bill created several IBA offenses, including a voyeurism offense which prohibits observing or recording someone in a private act/their genitals or underwear (Criminal Law Reform Bill 2019, section 377). It also prohibits viewing or possessing voyeuristic images (Criminal Law Reform Bill 2019, section 377BD) and distributing or threatening to distribute intimate images without consent (Criminal Law Reform Bill 2019, section 377BE). One of the aims of the Criminal Law Reform Bill 2019 was to clearly recognize different forms of IBA as unique offenses. As the Minister for Home Affairs Mr. K. Shanmugam noted in the second reading of the bill:

The current laws, in my view, do not adequately address the range of offenses involving voyeuristic recordings, and the distribution of such material on the Internet. We propose to introduce specific offenses involving "voyeurism" which will define the offending behavior, and provide for adequate punishments.... (Ministry of Home Affairs, 2019, p. 88)

Additionally, the Protection from Harassment (POHA) (Amendment) Act 2019 enhanced penalties for people who commit harassment in the context of an 
intimate relationship (both dating and married) and included making breaches of Protection Orders arrestable offenses where there is evidence of hurt, intimidation, or continued harassment (Protection from Harassment Amendment Act 2019, section 8B-C). It also implemented a specialist Protection from Harassment Court to manage POHA matters (Protection from Harassment Amendment Act 2019, section 16). These laws came into effect on January 1, 2020 and are a welcome change in terms of recognizing the rise of IBA behaviors, such as CSV (including "upskirting" and "downblousing"). Moreover, the criminalization of both the distribution of intimate images and threats to distribute intimate images also recognizes two modalities of IBA which have been raised as concerns by the SACC and within research (AWARE, 2019a; Vitis, 2020a). As such, they demonstrate the important roles that public condemnation, activism, and media reporting play in relation to legislative reform.

However, there are still questions about how and whether other modalities of abuse are recognized in current legislative protections, particularly in the context of family violence. In Singapore, family violence is defined within the Women's Charter (1961). The Charter defines nonphysical violence as "wrongfully confining or restraining a family member against his will" or "causing continual harassment with intent to cause or knowing that it is likely to cause anguish to a family member" (Women's Charter, 1961, section 64). The first provision makes no mention of nonphysical restraint as a result of contact-based harassment or surveillance, and the second emphasis on "intention" could also be refuted by abusers who use embedded technologies as part of their patterns of coercive control. Alternatively, contact-based harassment can easily be dismissed due to the social normalization of high-volume contact and the heteronormative acceptance of relationship surveillance (Levy, 2015). The term "continual harassment" could be applied to the range of abuses described above; however, the lack of clarity in relation to TFVW or TFCC (Dragiewicz et al., 2018) may complicate this. Therefore, while the Criminal Law Reform Bill 2019 explicitly recognizes the rise of IBA, it is also important to recognize the role that technologies have played within the varying and complex relations of domestic and family violence.

\section{Technology and Dating, Domestic, and Family Violence in Singapore}

As noted above, there has been limited research that has examined how technologies have shaped women's experiences of domestic violence in Singapore. In the interest of adding to this knowledge, in this section, I report findings from a research project which examined the role of technology in Singaporean women's experiences of dating, domestic, and family violence. This project involved semistructured interviews with 14 frontline workers in the fields of domestic violence, sexual violence, and LGBT support. Participants were identified and contacted through publicly available email addresses located on their organization's website. Participants were then interviewed at their places of employment and 
interviews focused on their observations of the role of technology in their clients' experiences of dating, domestic, and family violence. After data collection, I conducted a thematic analysis of their responses. In line with the international domestic violence literature (Dragiewicz et al., 2019; Harris \& Woodlock, 2019; Woodlock, 2013), frontline workers reported three main modalities of tech abuse: contact-based harassment; surveillance; and IBA. They also noted connections between these modalities and coercive and controlling behaviors.

\section{Contact-Based Harassment}

One of the most common forms of tech abuse reported by workers was contactbased harassment. This included cases where perpetrators would use phones mostly WhatsApp or SMS - to send abusive, insulting, controlling, or harassing messages. Participants noted that despite a complex technological landscape, the "standard" communication devices like phones were used far more commonly to harass and control during abusive relationships. These messages were identified as being both persistent and unwanted and involved gendered invective, threats, and in some cases threats to kill:

... I think the most common one would be through texting. To harass or even to threaten the victims.... There... could be repeated texts or calling and all these thing. It puts the receiver, the victims at a very unease mental states... the husband, because he will be texting the wife. Scolding, abusive language. Very harsh and [unclear] to the wife. (Participant C)

These accounts indicated that repeated, unwanted, and abusive messages were additional mechanisms through which perpetrators could enact abuse in high volume. One of the contexts in which contact-based harassment occurred was at separation. For example, workers reported that abusive messaging became apparent after a client took out a Personal Protection Order (PPO) and had attempted to separate or sought a divorce. This highlights what Dimond, Fiesler, and Bruckman (2011) describe as the technological "web of entanglement" (p. 419) and affirms international scholarship which has found that high volume/abusive messages are a common tactic used to reassert control and contact during separation (Dragiewicz et al., 2019; Woodlock, 2013). While in many cases messages were used to facilitate contact between perpetrator and victim-survivor, there were other cases where the perpetrator would engage in networked contact-based harassment. This was achieved by either enlisting extended members of the victim-survivor's direct community to harass on his behalf or threatening to expose or humiliate them within that community. For example, in one case, the perpetrator was blocked by the victim-survivor and in response he began threatening to contact her immediate circle of friends and family in order to humiliate or embarrass her. This aligns with other research which has shown that individual or networked contact-based harassment is 
facilitated through communication technologies and a technosocial landscape which enables networked social connections and collapses boundaries of space and time (NNEDV, 2014).

\section{Surveillance}

One of the most prominent modalities of abuse reported was the use of surveillance technologies to exert control. Participants discussed four types of surveillance. The first type was overt camera surveillance in the home. In these cases, abusers overtly installed cameras in the house to record spouses and family members. This footage was either passively recorded or actively reviewed by abusers and then used to issue correction at a distance. Second, participants discussed covert surveillance, involving the hidden installation or use of recording devices in the home, and third is the movement surveillance, where perpetrators used repeated messaging or the GPS capabilities on phone applications to restrict women's movement outside the home (Vitis, 2020b). One example was provided by a participant who articulated how apps with GPS capabilities were used for the purposes of control:

So situations where a couple is in a relationship where there's certainly controlling behaviors. So using of - I had to learn this from my client - certain apps that are GPS linked. So going on those apps and basically knowing where your partner is because you know what profile they're using. They're knowing that okay they're on and they're there and they're supposed to be somewhere else but they're there instead.... (Participant H)

The fourth type of surveillance was social surveillance. In these cases, the perpetrator would intrude women's devices, social media accounts, or emails or restrict access to communication devices in order to monitor and control who they were in contact with (Vitis, 2020b). Dragiewicz et al. (2019) argue that these experiences can be explained in relation to the wider inclusion of technology into forms of coercive control, as abusers increasingly rely on the surveillant affordances of digital media to both gain access to and exert control over women's lifeworlds. This was affirmed within these accounts which showed that technologies were used to create surveillant assemblages to restrict women's freedom and autonomy within their homes, social networks, and/or the public sphere. Importantly, these assemblages are supported by the rising consumer spyware industry and the affordable and accessible integration of surveillance into everyday devices (Harkin, Molnar, \& Vowles, 2020).

\section{Image-Based Abuse}

Workers did not indicate that IBA was prominent, although they were able to identify cases where IBA had taken place. One worker suggested that it was not 
common for husbands to take and store photos of their wives in Singapore. Another worker attributed this to Singapore being a conservative country and suggested that clients were not technologically proficient enough for such practices:

No, I think Singapore is quite conservative in the sense where they don't take videos of, yes, maybe they're not that sophisticated... in terms of thinking of take photos of, I don't know, sexual intimacy, or cultural kind of sensitive things. I think either they don't, I don't know, I think the mind of Singaporeans maybe, I don't know, maybe they're not so exposed to ideas like that. (Participant D)

Despite this, four workers spoke about incidents where boyfriends, husbands, or ex-husbands nonconsensually shared intimate images of their wives, girlfriends, or ex-wives with third parties. One participant noted that her client's partner shared her intimate images with an acquaintance on a chat room. Another worker described her wider professional experience in the school context, where boys had nonconsensually shared consensually obtained intimate images of girls with other boys as an accepted standard of dating and breaking up. The use of images for homosocial bonding, attaining status (Ringrose \& Harvey, 2015), or "doing masculinity" (DeKeseredy \& Schwartz, 2016, p. 3) was also noted by other participants. For example, one worker described a case at her workplace where a young woman reported that her boyfriend shared her intimate images with his friends:

The intentions initially wasn't - it wasn't to threaten the relationship. There was a friendly share with a close group of friends... the boyfriend didn't really practice discretion with his group of friends.... She only heard it from her friend who received that photo. Of course, she felt quite thrown off guard. (Participant M)

This reflects Ringrose and Harvey's (2015) finding that in school/peer contexts, boys " ... can gain value and reputational reward from possessing images of esteemed girls' bodies and the implication of sexual services from girls" (p. 214). It also indicates how images are used within homosocial contexts as a way of sustaining relationships between men or boys. Furthermore, it accords with recent reports that men and boys are using online sites or private chat groups to nonconsensually share nude images of Singaporean women with peers.

Images were also used as a way of sustaining control in an abusive relationship, particularly at separation. In one case, a client's husband gave his current partner access to a hard drive where her nude images were stored. In another, a woman's husband shared her intimate images with her new partner in order to seek revenge:

So, he warned him that "this is the kind of woman that you are going to marry - if you're eventually going to marry - and I felt being betrayed by her," that kind of thing. So, he's like, in a way 
like blackmailing.... It's that warning him that "are you sure you want to get, you want to marry her in the future?" "She has been my wife and she's doing all this kind of thing behind my back - the mistress having an affair with you." (Participant F)

This aligns with research into both domestic violence and IBA which has shown that separation is a common context for men to circulate intimate images without consent for the purpose of harming or humiliating women, as part of a narrative of "pay back" (Bruton \& Tyson, 2017; State of Victoria, 2016). Therefore, while some workers claimed that this practice was not commonplace in Singapore, the casual ways in which men shared these images, coupled with wider reports of IBA in the community, raise questions about whether this assessment is accurate, particularly considering the varied nature of these reports which include peer sharing in schools, peer sharing online, and instrumental and coercive use of images.

\section{Training and Support}

None of the 14 participants I spoke to discussed receiving training on TFVW or TFCC. In some cases, they noted that they had limited knowledge of the nature, deployment, and impacts of TFCC. For example, one participant reflected on a client whose husband installed cameras in the home:

If I recall, I was probably a lot more interested in the physical line that's being perpetrated. I didn't ask about how it felt being having cameras watching you all the time. Maybe it was a part, I didn't ask, I felt, I suspected, I didn't, we didn't know what to do with that. I felt as if I ask her questions, because I kind of know where, what you could do with it. I think I, I probably felt as helpless as well, I suspect. (Participant K)

Moreover, some reported that they learned about tech abuse from their clients. For example, one worker stated that she found out from a client that apps were GPS linked and could enable abusers to stalk their partners at a distance. Another participant reported that they were uncertain as to how the abuser had managed to track their client via their devices:

I had this client where the husband had control of the wife's WhatsApp messages. He somehow was tracking it via his laptop. I don't know how he did it, but this was what the client told me. Whoever she sends a text message, whoever she calls or whatever, husband is aware and also whereabouts. (Participant E)

TFCC training for police and support staff is crucial. Without appropriate training, workers in these fields may not recognize the range of technologies being used, their interrelationship with coercive control, and how to advise women on 
appropriate safety planning (Dragiewicz et al., 2019). For example, when coercive and controlling behaviors are reported, police may lack the knowledge required to check devices or advise victim-survivors on how to adequately record evidence (Dragiewicz et al., 2019). The onus is then placed upon the victim-survivor to gather complex device-based evidence without technical support (Dorozenko \& Chung, 2018). These knowledge gaps are then carried through to the courts where victim-survivors report that the true seriousness of TFCC is not adequately recognized (Dragiewicz et al., 2019).

Similarly, service providers have acknowledged that face-to-face training, which provides up-to-date information on the various technologies being deployed by abusers and how to conduct device checks, is important (Dragiewicz et al., 2019). For example, a review of WESNET's "Safer technology for women training" found that workers who completed the training felt more confident in advising clients on how to address contact-based harassment (Dorozenko \& Chung, 2018). They were also better able to identify the different modalities of tech abuse and implement relevant safety strategies (Dorozenko \& Chung, 2018). Importantly, this evaluation highlighted that, without training, workers may rely on "common sense" strategies (such as blocking) to protect women from stalking and abuse; however, this may further compromise their safety (Dorozenko \& Chung, 2018). This is a key issue, as research with practitioners has shown that strategies which prioritize restricting contact via devices or changing numbers do not fully address the problem (Harris \& Woodlock, 2019).

What was evident, however, was that women coming to these services had developed their own safety strategies that allowed them to maintain some autonomy while simultaneously managing the abuser's controlling behaviors:

She mentioned that usually she will delete all this information or whatever calls that she makes out before going back home. Also, when we contact her or message her, she will delete. (Participant E)

Then eventually the husband kept checking her phone, and then she eventually registered another phone, another line secretly. She keeps the phone somewhere else. (Participant F)

She told me that she can't deal with the text messages, she just blocks them, so she's able to then restrict these messages by blocking him totally, even blocking her husband from texting her, from messaging her, even from email. She's able to block all access of contacts with the husband. (Participant D)

Similarly, Dragiewicz et al. (2019) found that women were best placed to assess their own safety, and this may mean staying in contact with the perpetrator via controlled devices. However, limited formal training for workers raises important questions about the pressure placed on victims-survivors to develop the technological skills required to both understand the dynamics of TFCC and create techinclusive safety strategies (Harris \& Woodlock, 2019). 


\section{Conclusion}

This research makes no claims about the prevalence of TFCC; however, the types of abuses reported by workers accord with findings from outside Singapore which have shown that TFCC is a key issue for victim-survivors of domestic and family violence (Dragiewicz et al., 2019; Woodlock, 2013). As such, these findings suggest that the next large-scale survey of VAW in Singapore includes these technological modalities in order to obtain a more accurate understanding of the prevalence of TFVW and TFCC in the Singaporean context. These findings also demonstrate the need for qualitative research which draws directly from the insights of victims-survivors. The current Singaporean research on domestic violence and TFVW, mine included, has focused on service data and interviews with service providers. As such, it is important that contemporary empirical scholarship includes both large-scale surveys to highlight the prevalence of this problem, in addition to in-depth interviews with victims-survivors to better understand the impact of communication, digital, and internet technologies on their experiences of violence. This is of particular importance during this period of legislative reform in Singapore. In order to assess the impacts of the recently implemented IBA offenses (Criminal Law Reform Bill, 2019) and changes emerging from the Protect from Harassment (Amendment) Act 2019, research which draws upon the experiences of victims-survivors of TFVW who have pursued these formal avenues of intervention is required. This work is needed to ensure that the experiences of victims-survivors guide current and future law reform, prevention strategies, and service responses.

As noted above, these abuses have come to the public's attention through media reporting, protest, and political support for including (some) instances of IBA in the Criminal Law Reform Bill 2019. This political engagement demonstrates some awareness of tech-based abuses. However, to fully realize the extent of VAW and the role of technology in that violence, these abuses need to be recognized as part of the patterns of gendered, sexual, domestic, intimate partner, and family violence (Vitis, 2020a). Without this, it will be difficult to uncover the complexities of controlling behavior in domestic violence or address women and girls' experiences of violence in the everyday. This work is already underway. AWARE has recently launched their Alt-Ctrl program, which aims to provide a platform for community members to develop projects which address tech and gender violence and includes prevention, policing, and pathways to justice (AWARE, 2019b). However, there are additional avenues to consider. More consultation is needed with workers to map knowledge and knowledge gaps in order to develop appropriate training programs. On February 17, 2020, the Ministry of Home Affairs and the Ministry of Social and Family Development announced a new task force which will respond to family violence by setting up a dedicated hotline and placing social workers in all police divisions to assess victims and refer them to relevant agencies (CNA, 2020). It is important to ensure that TFCC and tech abuse training for police and frontline workers is on the agenda for this task force. These efforts could also be 
supported by ensuring the community is aware of the relationships between technology and coercive control. This could be expressed by updating public service announcements developed by the National Family Violence Networking System, which provide descriptions of dating, domestic, and family violence without mentioning the role of technology (NFVNS, 2018).

\section{Notes}

1. Camera sexual voyeurism (CSV) is the use of camera devices to record intimate images of another person without their consent, for instance, taking images up a woman's skirt or shorts, or down her top, or planting a hidden camera to record a person in private spaces.

2. Tinder Nightmares and ByeFelipe are Instagram accounts that repost women's experiences of negative or objectionable behavior on dating applications.

3. While TFCC is diverse, the following behaviors are prominent manifestations: contact-based harassment (repeated, unwanted use of communication, digital and internet technologies for contact); IBA (the nonconsensual, production, possession, and dissemination of intimate images or threats to disseminate intimate images); and surveillance (the use of varying technologies to monitor) (Dragiewicz et al., 2019).

4. "Upskirting" is only one example of camera technology being used to record without consent. In order to capture other acts, I use the term "camera sexual voyeurism" (CSV).

5. An "insult of modesty" offense is defined as sexual harassment, which includes CSV.

6. This carries a prison term ranging from 2 years for making an obscene film to 6 months for possessing a single obscene film.

7. WESNET is the national peak body for specialist women's domestic violence services in Australia.

\section{References}

Alkhatib, S. (2019, March 28). Man linked with Sammyboy Forum jailed for filming women in toilet. The Straits Times. Retrieved from https://www.straitstimes.com/ singapore/

Ang, J. (2019a, April 26). Exclusive interview: Posting my story on Instagram about NUS Peeping Tom was last resort, says Monica Baey. The Straits Times. Retrieved from https://www.straitstimes.com/singapore/

Ang, L. (2019b, October 20). Police looking into another Telegram chat group allegedly circulating obscene materials. The Straits Times. Retrieved from https:// www.straitstimes.com/singapore/

AWARE. (2019a). A recap: Taking ctrl, finding alt 2019. Retrieved from https:// www.aware.org.sg/2019/11/a-recap-taking-ctrl-finding-alt-2019/

AWARE. (2019b). Taking ctrl, finding alt contest. Retrieved from https://www. aware.org.sg/tfsvcontest/ 
Bouhours, B., Chan, W.C., Bong, B., \& Anderson, S. (2013). International violence against women survey: Final report on Singapore. Retrieved from https://ssrn.com/ abstract $=2337291$

Bruton, C., \& Tyson, D. (2017). Leaving violent men: A study of women's experiences of separation in Victoria, Australia. Australian and New Zealand Journal of Criminology, 51(3), 339-354. doi:10.1177/0004865817746711

Carrington, K., Bull, M., \& Vitis, L. (2020). Gender-based violence: Case studies from the Global South. In S. Walklate, K. Fitz-Gibbon, J. Maher, \& J. McCulloch (Eds.), The Emerald handbook of feminism, criminology and social change (pp. 373-394). Bingley: Emerald Publishing Limited.

Chan, W. C. (2013). Violence against women in Singapore: Initial data from the International Violence Against Women Survey. In J. Liu, B. Hebenton, \& S. Jou (Eds.), Handbook of Asian criminology (pp. 329-342). New York, NY: Springer.

Chong, E. (2015, December 23). Jail for taking upskirt videos of 21 women. The Straits Times. Retrieved from https://www.straitstimes.com/singapore/

Chong, E. (2017, September 28). Ex-bank officer jailed 24 weeks for taking upskirt videos of strangers and colleague. The Straits Times. Retrieved from https:// www.straitstimes.com/singapore/

CNA. (2020, February 17). MHA, MSF set up joint task force to tackle family violence. Channel News Asia. Retrieved from https://www.youtube.com/watch? $\mathrm{v}=\mathrm{NYPa} 3 \mathrm{OBGg} 1 \mathrm{Y}$

Criminal Law Reform Bill. (2019). Section 377BD, 377BE. Retrieved from https:// sso.agc.gov.sg/Bills-Supp/6-2019/Published/20190211?DocDate=20190211

DeKeseredy, W., \& Schwartz, M. (2016). Thinking sociologically about image-based sexual abuse: The contribution of male peer support theory. Sexualization, Media, \& Society, 2(4), 1-8. doi:10.1177/2374623816684692

Dimond, J., Fiesler, C., \& Bruckman, A. (2011). Domestic violence and information communication technologies. Interacting with Computers, 23(5), 412-421. doi: 10.1016/j.intcom.2011.04.006

Domestic and Family Violence Death Review and Advisory Board. (2017). Domestic and Family Violence Death Review and Advisory Board: 2016/17 annual report. Retrieved from https://www.courts.qld.gov.au/_data/assets/pdf_file/0003/541947/ domestic-and-family-violence-death-review-and-advisory-board-annual-report-201617.pdf

Dorozenko, D., \& Chung, D. (2018). Research and evaluation of the safer technology for women training and the safe connections program. Retrieved from https://wesnet.org.au/wp-content/uploads/sites/3/2019/10/Safe-Connections-Evaluation_TelstraReport_-Final.pdf

Dragiewicz, M., Burgess, J., Matamoros-Fernández, A., Salter, M., Suzor, N. P., Woodlock, D., \& Harris, B. (2018). Technology facilitated coercive control: Domestic violence and the competing roles of digital media platforms. Feminist Media Studies, 18(4), 609-625. doi:10.1080/14680777.2018.1447341

Dragiewicz, M., Harris, B., Woodlock, D., Salter, M., Easton, H., Lynch, A., \& Milne, L. (2019). Domestic violence and communication technology: Survivor experiences of intrusion, surveillance and identity crime. Retrieved from https:// accan.org.au/grants/completed-grants/1429-domestic-violence-and-communicationtechnology-victim-experiences-of-intrusion-surveillance-and-identity-theft 
Films Act 1998 Rev. Ed., section 29.1, 29.3, 30.1. Retrieved from https://sso.agc.gov.sg/ Act/FA1981

Gillet, R. (2019). Everyday violence: Women's experiences of intimate intrusions on tinder. Doctoral dissertation, Queensland University of Technology. Retrieved from https://eprints.qut.edu.au/131121/

Goh, Y., \& Yip, M. (2014). The Protection from Harassment Act 2014: Legislative comment. Singapore Academy of Law Journal, 26, 703-726. Retrieved from ssrn.com/abstract $=2531196$

Hand, T., Chung, D., \& Peters, M. (2009). The use of information and communication technologies to coerce and control in domestic violence and following separation. Australian Domestic \& Family Violence Clearinghouse, Paper 6. Retrieved from https://research-repository.uwa.edu.au/en/publications/the-use-of-information-andcommunication-technologies-to-coerce-a

Harkin, D., Molnar, A., \& Vowles, E. (2020). The commodification of mobile phone surveillance: An analysis of the consumer spyware industry. Crime, Media, Culture: An International Journal, 16(1), 33-60. doi:10.1177/1741659018820562

Harmer, E., \& Lumsden, K. (2019). Online othering: An introduction. In K. Lumsden, \& E. Harmer (Eds.), Online othering (pp. 1-33). Cham: Springer International Publishing.

Harris, B. A., \& Woodlock, D. (2019). Digital coercive control: Insights from two landmark domestic violence studies. British Journal of Criminology, 59(3), 530-550. doi:10.1093/bjc/azy052

Hayes, R. M., \& Dragiewicz, M. (2018). Unsolicited dick pics: Erotica, exhibitionism or entitlement? Women's Studies International Forum, 71, 114-120. doi:10.1016/ j.wsif.2018.07.001

Henry, N., Powell, A., \& Flynn, A. (2017). Not just 'revenge pornography': Australians experiences of image-based abuse: A summary report. Retrieved from https:// www.rmit.edu.au/content/dam/rmit/documents/college-of-design-and-social-context/ schools/global-urban-and-social-studies/revenge_porn_report_2017.pdf

Jane, E. (2017). Feminist flight and fight responses to gendered cyberhate. In M. Segrave, \& L. Vitis (Eds.), Gender, technology and violence (pp. 45-61). London: Routledge.

Levy, K. (2015). Intimate surveillance. Idaho Law Review, 51(3), 679-694. Retrieved from https://heinonline-org.ezproxy.lib.rmit.edu.au/HOL/Page?lname $=\&$ public $=$ false \&collection $=$ journals $\&$ handle $=$ hein $. j o u r n a l s / i d l r 51 \&$ men_hide $=$ false $\&$ men_ tab $=$ toc\&kind $=$ \&page $=679$

Maher, J. M., McCulloch, J., \& Fitz-Gibbon, K. (2017). New forms of gendered surveillance? Intersections of technology and family violence. In M. Segrave, \& L. Vitis (Eds.), Gender, technology and violence (pp. 14-27). London: Routledge.

Ministry of Home Affairs. (2019). Second reading of Criminal Law Reform Bill. Speech by Mr. K Shanmugam. Minister for Home Affairs and Minister for Law. Retrieved from https://www.mha.gov.sg/newsroom/in-parliament/parliamentaryspeeches/news/second-reading-of-criminal-law-reform-bill-speech-by-mr-k-shanmugam-minister-for-home-affairs-and-minister-for-law

Mohanty, C. (2012). Under Western eyes: Feminist scholarship and colonial discourses. In M. G. Durham, \& D. M. Kellner (Eds.), Media and cultural studies: Key works (pp. 347-364). Malden, MA: Wiley-Blackwell. 
NFVNS. (2018). What is family violence. The national family violence networking system. Retrieved from https://www.msf.gov.sg/breakthesilence/SitePages/Home_ Family.aspx?family $=1$

NNEDV. (2014). A glimpse from the field: How abusers are misusing technology. Washington, DC: Safety Net Technology Safety Survey. Retrieved from https:// static1.squarespace.com/static/51dc 541ce4b03ebab8c5c88c/t/54e3d1b6e4b08500 fcb455a0/1424216502058/NNEDV_Glimpse+ From + the+Field+-+2014.pd

Penal Code 2008 Rev. Ed., section 509. Retrieved from https://sso.agc.gov.sg/Act/ PC1871?

Powell, A., Henry, N., Flynn, A., \& Scott, A. (2019). Image-based sexual abuse: The extent, nature, and predictors of perpetration in a community sample of Australian residents. Computers in Human Behavior, 92, 393-402. doi:10.1016/ j.chb.2018.11.009.

Protection from Harassment (Amendment) Act 2019. Retrieved from https:// sso.agc.gov.sghttps://sso.agc.gov.sg/Acts-Supp/17-2019/Published/20190610?DocDate $=20190610 \&$ ViewType $=$ Within\#: $:$ text $=$ The $\% 201$ ong $\% 20$ title $\% 20$ to $\% 20$ the, and $\% 20$ to $\% 20$ provide $\% 20$ for $\% 20$ the

Ringrose, J., \& Harvey, L. (2015). Boobs, back-off, six packs and bits: Mediated body parts, gendered reward, and sexual shame in teens' sexting images. Continuum, 29(2), 205-217. doi:10.1080/10304312.2015.1022952.

Sam's Forum. (2020). Sam's Forum: Where REAL people discuss what REALLY matters in their lives. Retrieved from www.samsimply.rocks

Southworth, C., Finn, J., Dawson, S., Fraser, C., \& Tucker, S. (2007). Intimate partner violence, technology, and stalking. Violence Against Women, 13(8), 842-856. doi:10.1177/1077801207302045.

State of Victoria. (2016). Royal Commission into Family Violence: Summary and recommendations (Parl Paper No 132). Retrieved from http://rcfv.archive. royalcommission.vic.gov.au/MediaLibraries/RCFamilyViolence/Reports/RCFV_ Full_Report_Interactive.pdf

Tan, T. M. (2019, November 25). Tech-enabled sexual violence cases almost triple since 2016, says Aware. The Straits Times. Retrieved from https://www.straitstimes.com/singapore/

Thompson, L. (2018). "I can be your Tinder nightmare": Harassment and misogyny in the online sexual marketplace. Feminism \& Psychology, 28(1), 69-89. doi:10.1177/ 0959353517720226.

Vitis, L. (2020a). Private, hidden and obscured: Image based sexual abuse in Singapore. Asian Journal of Criminology, 15(1), 25-43. doi:10.1007/s11417-01909293-0.

Vitis, L. (2020b). Surveillance in the city: The role of surveillance in women's experiences of domestic violence in Singapore, perspectives from frontline workers. Unpublished Work.

Vitis, L. (2020). Media representations of camera sexual voyeurism in Singapore: A medicalised, externalised and community problem. Feminist Media Studies. Online First. doi:10.1080/14680777.2020.1810095

Vitis, L., Joseph, A., \& Mahadevan, D. (2017). Technology and sexual violence: SACC summary report. Retrieved from https://www.aware.org.sg/wp-content/ uploads/SACC-TFSVH-Report-Final-report.pdf 
Vitis, L., Naegler, L., \& Ahmad Salehin, M. S. (2019). The Challenges of online networked ethnographic: Researching image based abuse online. Paper presentation. The American Society of Criminology Conference, San Francisco, CA.

Women's Charter 1961 section 64. Retrieved from https://sso.agc.gov.sg/Act/WC1961

Woodlock, D. (2013, Spring/Summer). The rise of technology-based stalking. DVRCV Advocate, 2, 4-7. 